\title{
Rapid and Continuous Extraction of Methyl Red from Wastewater Using Counter Current Chromatography
}

\author{
Nasrin Adli'1, Azam Azimvand2 ${ }^{2}$, Zinolabedin. Bashiri Sadr'1, \\ Moharam Moharamzadeh1, Hossein Salar Amoli ${ }^{*}$ \\ ${ }^{1}$ Chromatography Lab, Faculty of Chemical Technology, Iranian Research Organization for Science and \\ Technology, Tehran, Iran \\ ${ }^{2}$ Payam Noor University, Gazvin Branch, Gazvin, Iran \\ Email: 'salar@irost.org
}

Received 4 March 2016; accepted 10 June 2016; published 13 June 2016

Copyright (C) 2016 by authors and Scientific Research Publishing Inc.

This work is licensed under the Creative Commons Attribution International License (CC BY).

http://creativecommons.org/licenses/by/4.0/

(c) (i) Open Access

\section{Abstract}

A new prototype and simple low speed counter current chromatography (LSCCC) has been fabricated and a laboratory work has been carried out for rapid and continuous removal of methyl red from wastewater using xylene as an extractant. The distribution ratio (D) and percentage of recoveries were calculated. The optimum concentration for extraction of methyl red was in the range of $2 \times 10^{-4}$ to $8 \times 10^{-4} \mathrm{~mol} \cdot \mathrm{L}^{-1}$. Maximum extraction achieved at $\mathrm{pH}$ range of 2 to 4.5 . Various dye concentrations and solvent effects were studied to optimized conditions. It was shown that when the ratio of the organic phase to aqueous phase increased to more than $3: 1$, the striping efficiency decreased sharply. The experiments were carried out for 5 times and the highest extraction achieved was 99.8 per cent by two-solvent system LSCCC in just 5 minutes. Real wastewater samples were analyzed and the efficiency of the technique was compared with liquid-liquid extraction (LLE). In practice it was shown that although both techniques are rapid, the efficiency of the LSCCC is much better than LLE.

\section{Keywords}

Counter Current Chromatography, Rapid Extraction, Methyl Red, Continuous Removal

\section{Introduction}

It is estimated that more than 100,000 commercially available dyes with over $7 \times 10^{5}$ tons of dyestuff are produced

${ }^{*}$ Corresponding author.

How to cite this paper: Adli, N., Azimvand, A., Sadr, Z.B., Moharamzadeh, M. and Amoli, H.S. (2016) Rapid and Continuous Extraction of Methyl Red from Wastewater Using Counter Current Chromatography. Materials Sciences and Applications, 7, 307-315. http://dx.doi.org/10.4236/msa.2016.76028 
annually [1] [2]. As usual dyes are used in textile, paper, plastic, leather and many other industries. So, dyes releasing from these industries cause eco-toxic hazard and may eventually affect human through food chain. In addition, some dyes are either toxic or mutagenic and carcinogenic [3] [4]. It is reported that, approximately one million kilograms per year of a dye are discharged into water streams just by the textile industry [5] [6]. The most widely used industrial dyes are azo dyes, which constitute $60 \%$ - 70\% of all produced dyestuffs [7]-[9].

The extensive use of dyes could spread carcinogenic, mutagenic, allergenic and environmental pollution [10]. It is, therefore, essential to remove the dye from wastewater or treat it in such a way so as to minimize the damage to the environment [11] [12]. When a dye is stable under all conditions (exposure to sunlight, water, soap, soil etc.), it becomes more difficult to treat it in wastewater [13]. These hazardous contaminants must be removed from waste effluents prior to discharge. Azo dyes are exclusively organic compounds consisting of a diazotized amine coupled to an amine or a phenol and contain one or more azo $(-\mathrm{N}=\mathrm{N}-)$ linkages [14] [15].

Methyl red is a kind of anionic azo dye [16] and causes irritation of the eyes, skin and digestive tract if inhaled/swallowed [17] [18].

Coagulation, flocculation, oxidation or ozonation, membrane separation and activated carbon adsorption are known as the conventional methods for treating wastewater containing dyes [19]. Nowadays much attention has been given to more effective and rapid chemical separation techniques such as solvent extraction which is used for the purification, enrichment and analysis of various compounds in mixtures. This technique is based on the principle that a dye can distribute itself in a certain ratio between immiscible solvents. Therefore the selection of both a diluent and an extractant determines the equilibrium for a given system, so, efficiency of extraction process depends on its mass transfer rate [20] [21]. Muthuraman reported the extraction and recovery of methylene blue from industrial wastewater by LLE, using benzoic acid as the extractant [22]. Under optimized conditions, $98 \%$ of the dye was extracted from aqueous solutions and the extracted dye in the organic phase was back extracted into sulphuric acid solutions. Similarly, methyl red dye was extracted and recovered from industrial wastewater by LLE technique. Extraction efficiency varied from $90 \%$ to $97 \%$ at the aqueous to organic phase and the loaded dye was back extracted into sodium hydroxide solutions [23]. Recent literature is an effective and attractive process for the decontamination of the dye-containing effluents and many researchers have adopted the adsorption approaches [24] [25]. The other methods such as coagulation and flocculation [26]-[28] and other materials such as activated carbon are also used for the removal of methyl red from simulated wastewater [29]-[31]. In the present work the extraction of anionic dyes namely methyl red from wastewater solutions was carried out by Low Speed Counter Current Chromatography (LSCCC). This is a modern technique for the separation and purification of the samples [32]-[36]. CCC is a form of support-free chromatographic system. It is simple operation and less time-consuming technique. It is essentially suitable for separation and purification of high polar compounds. Using CCC in preparative and continuous separation is steadily growing [37] [38].

In our best knowledge, no paper has been reported on the use of LSCCC for the extraction of dyes from wastewater. The fundamental parameters such as $\mathrm{pH}$, effect of time, stripping agent, initial dye concentration and effect of diluents on dye extraction efficiency were studied. Using LSCCC a high efficient recovery for methyl red was obtained. The method was compared with data obtained at the same conditions with liquid-liquid extraction (LLE) method.

\section{Experimental}

\subsection{Materials and Apparatus}

All chemicals used in this study were of analytical grade reagents. Methyl red, xylene, sulphuric acid, sodium hydroxide were obtained from Merck. UV-visible spectrophotometer (Lambda 25) was used to measure the absorbance of dyes to establish its $\lambda$ max and its concentration. The $\mathrm{pH}$ was measured by a $\mathrm{pH}$ meter (model 320 Mettler Toledo Instruments). For agitation of solutions a mechanical stirrer (IKD_Ks50) was used. Xylene was used as an extractant and distilled water was used for preparation of the dye solution. The $\mathrm{pH}$ was adjusted by sulphuric acid.

\subsection{LSCCC Instrument}

The LSCCC was constructed in our lab. The column is made from a long piece of polytetrafluoroethylene (PTFE) tubing by winding it around a cylindrical holder hub to make multiple layers of coil. The column is 
mounted in a centrifuge rotor, which rotates around the central axis at a known angular velocity $(\omega)$, as in an ordinary centrifuge system.

The length of the column was a 1.5 meter tube with a $6 \mathrm{~mm}$ diameter and the solutions were injected using an HPLC pump (Water, model 515, M Ilford MA). The stationary and mobile phases were pumped into multilayer column at a flow rate of $1 \mathrm{ml} / \mathrm{min}$ in the head to tail direction.

The stationary upper phase [(xylene) $(20 \mathrm{~mL})]$ loaded into the column by syringe. Then a volume of the prepared aqueous dye solution $(20 \mathrm{~mL})$ introduced into the column and head and tail of column was interconnected. The column is rotated for a known time at a very low speed about 15 to $60 \mathrm{rpm}$. The effluent mixture was transferred into a separating funnel and was allowed to settle both layers. Aqueous layer (lower phase) was taken for absorbance measurement. Chemical structure of the methyl red (Figure 1) contains one (-N=N-) linkage and the wavelength of maximum absorption ( $\lambda$ max) for methyl red was $520 \mathrm{~nm}$. Characteristics of methyl red are described in Table 1. The distribution ratio (D) and percentage of extraction (E) were calculated by the Equations (1) and (2):

$$
\begin{gathered}
\mathrm{D}=[\text { methyl red }]_{\mathrm{O}} /[\text { methyl red }]_{\mathrm{A}} \\
\mathrm{E}=100 \times\left([\text { methy red }]_{\mathrm{AB}}-[\text { methyl red }]_{\mathrm{AF}}\right) /[\text { methyl red }]_{\mathrm{AB}}
\end{gathered}
$$

where [methyl red $]_{\mathrm{O}}$ is the methyl red concentration in organic phase (mol/L), [methyl red $]_{\mathrm{A}}$ is the methyl red concentration in aqueous phase. [methy red $]_{\mathrm{AB}}$ and $[\text { methyl red }]_{\mathrm{AF}}$ are the initial and final concentration of methyl red in aqueous phase before and after extraction, respectively.

To study the effect of the stripping agent, $V_{0} \mathrm{~mL}$ extractant and $V_{0} \mathrm{~mL}$ sodium hydroxide solution as stripping agent added together into the LSCCC column and rotated at $60 \mathrm{rpm}$. The content was then transferred into a separating funnel. The aqueous phase at the bottom of the separating funnel was taken for dye concentration measurements.

\subsection{Liquidé-Liquide Extraction Procédure}

The organic solvent (xylene) used for extraction was added to the known volume prepared aqueous dye solution in a glass-stoppered bottle and the glass-stoppered bottle was shaken in a shaker at $60 \mathrm{rpm}$. The mixture was then transferred into a separation funnel. Then the extracted dye was taken for absorbance measurement at $520 \mathrm{~nm}$.

\section{Results and Discussion}

\subsection{LSCCC Mechanism}

The mechanism of the CCC separation is based on the Archimedean screw force which mixes two solvent and<smiles>CN(C)c1ccc(/N=N/c2ccccc2C(=O)O)cc1</smiles>

Figure 1. Chemical structures of anionic methyl red.

Table 1. Characteristics of methyl red.

\begin{tabular}{ccccc}
\hline MW & Number of azo bonds & Wavelength maximum (nm) & Molecular formula & Trademark \\
\hline 269.31 & 1 & $520 \mathrm{~nm}$ & $\mathrm{C}_{15} \mathrm{H}_{15} \mathrm{~N}_{3} \mathrm{O}_{2}$ \\
\hline
\end{tabular}


yields excellent partition efficiency for a large scale sample. The CCC technique also faces to some problems such as band broadening due to longitudinal phase mixing and needs high column pressure. In order to cope with these problems, we have developed a short column, low speed CCC (LSCCC), which causes rapid circular motion of two solvent phases in cylindrical compartment.

Figure 2 shows the LSCCC as a prototype, has been constructed in chromatography lab-IROS. The holder, rotates on its own axis while revolving around the central axis.

When the filled coiled is held horizontally and slowly rotated on its own axis, both immiscible solvents (heavier and lighter) moves toward one end of the coil. The slow rotation could establish a hydrodynamic equilibrium between the two solvents. In this condition and under hydrodynamic equilibrium, one phase can move at the head, while the other phase retaining in the coil, causes solutes to be subjected to an efficient partition process and separation according to its partition coefficient between two liquids. In two solvent system the aqueous phase was the lower one, and extraction solution was pumped into the LSCCC column eluted by the mobile phase. After completion of the first cycle, the second one could be carried out by the same procedure. Obtained data indicated that both spiral effect and Archimedean screw force contribute to a high partition efficiency.

For this research work five important factors have been studied to evaluate the performance of the extraction method. These factors are stripping agent, effect of $\mathrm{pH}$, effect of initial dye concentration, time and dilution effects which are discussed in following sections.

\subsection{Stripping Studies}

The efficiency of separation of methyl red from aqueous phase mainly depend on a suitable solvent system. To obtain optimal two-phase solvent system, different solvents were used as mobile phases. The solvents examined were benzene, toluene, xylene and hexane. Among them the extraction efficiency of the benzene, toluene and xylene were acceptable while hexane was unable to extract dye from aqueous solution. Figure 3 shows that in all cases the efficiency of the LSCCC is more than LLE technique. Based on this experiment, and because of its less toxic effect compared to benzene and toluene and it's more effective than hexane to study the extraction of methyl red from aqueous solution, xylene was used as an extractant by a new method called Low Speed CCC. An optimal solvent system composed of xylene-water (1:1, v/v) was selected for LSCCC separation of ionic methyl red from the industrial wastewater. Various factors such as the effects of $\mathrm{pH}$, initial dye concentration and equilibration time on extraction efficiency of methyl red from aqueous solution were performed.
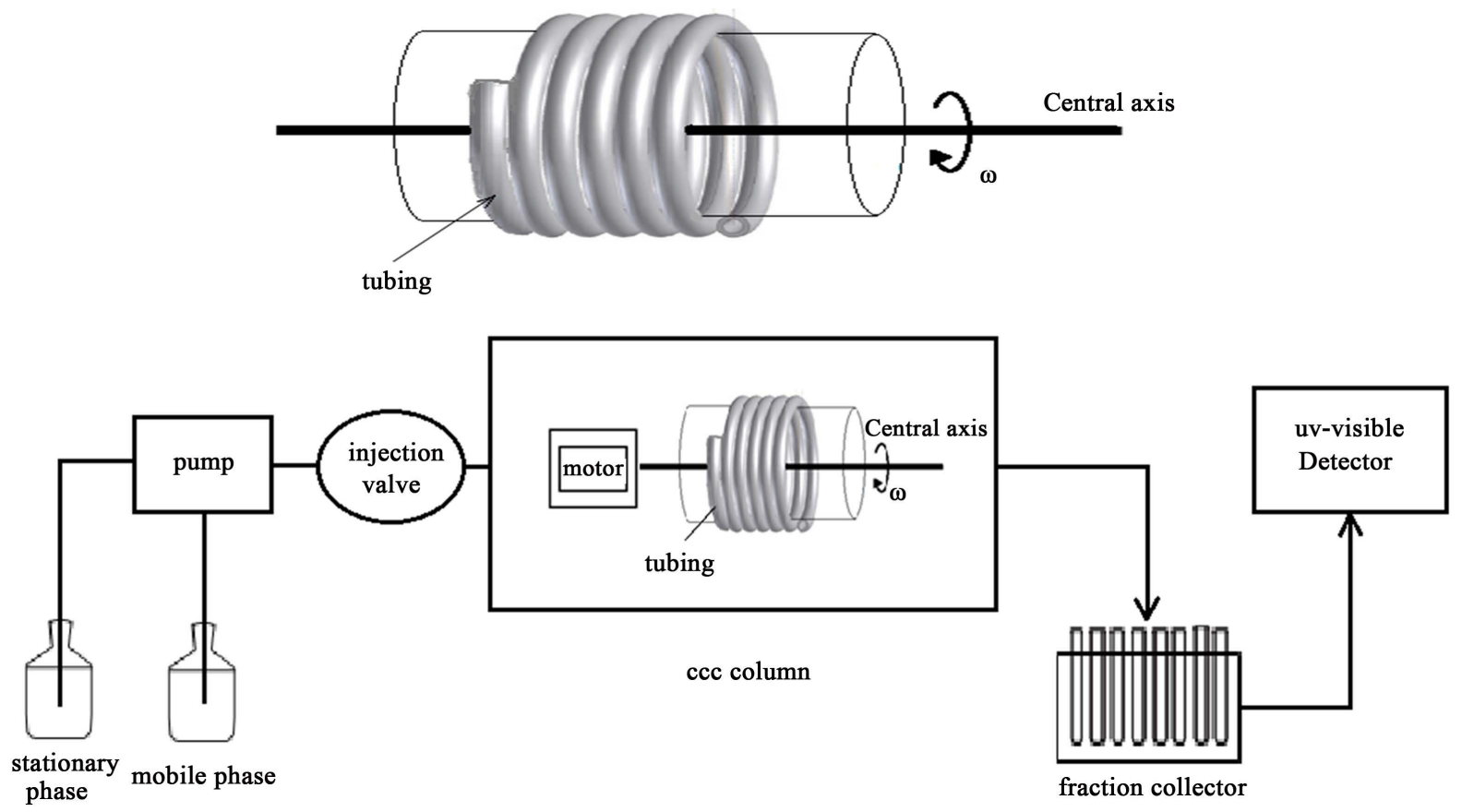

Figure 2. An illustration of LSCCC column. 


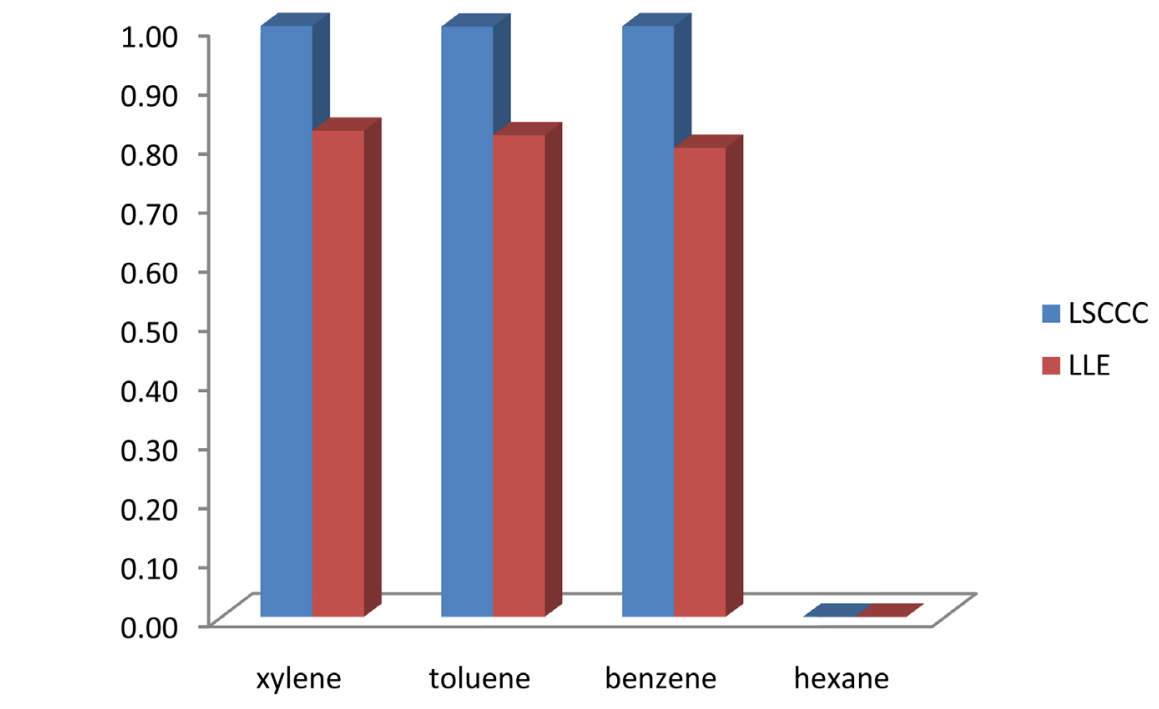

Figure 3. The effect of solvent on extraction of methyl red using LSCCC and LLE.

The extraction phase ratio studies, shows that maximum efficiency could be achieved when phase ratio is 1:1 to 3:1 (aqueous phase to organic phase). When the phase ratio increase to more than 4:1 and 5:1 the extraction efficiency dropped from $98 \%$ to just 91 and 83 percent respectively.

The organic solvent has been used after the first extraction and again interred into the LSCCC column to reextract methyl red from aqueous solution. Table 2 shows that the efficiency of the extraction was constant up to 4 cycles and then decreased smoothly.

\subsection{Effect of $\mathrm{pH}$ in the Aqueous Phase}

The effects of initial $\mathrm{pH}$ on extraction percentages of dyes were researched over a range of $\mathrm{pH}$ values from 1 to $7.5 \pm 0.1$ at $25^{\circ} \mathrm{C}$. The results show that extraction efficiency decreased with increasing $\mathrm{pH}$. The maximum extraction of dye was noticed at $\mathrm{pH} 2-4.5$ as shown in Figure 4. At low pH and $\mathrm{pH}>4.5$, the extraction efficiency decreased sharply. At the low $\mathrm{pH}, \mathrm{H}^{+}$ion concentration was increased in the solution and combines with anionic methyl red, so improves its solubility in xylene. At high $\mathrm{pH}$, the methyl red is in its unionized form, so it shows hydrophobic interaction with the stationary phase. It was shown that a sudden change in $\mathrm{pH}$ value causes to extreme changes in the retentions of the methyl red. To study other factors, the $\mathrm{pH}$ maintain at $2.5 \pm 0.1$ at $25^{\circ} \mathrm{C}$ and the aqueous phase concentration was maintained at $2 \times 10^{-4} \mathrm{~mol} / \mathrm{L}$.

\subsection{The Effect of Initial Dye Concentration in Aqueous Phase}

The effect of initial dye concentration in aqueous phase on the extraction efficiency of the methyl red were investigated in the range of $1 \times 10^{-4}$ to $8 \times 10^{-4} \mathrm{~mol} / \mathrm{L}$.

Extraction efficiency was not significantly changed in these range. But generally the results show that extraction efficiency first increased with increase the concentration up to $2 \times 10^{-4} \mathrm{~mol} / \mathrm{L}$ and more than this amount, efficiency decreased sharply (Figure 5). It seems that at higher dye concentration, xylene could not completely extract the dye from the aqueous phase.

\subsection{Effect of Equilibration Time}

The extraction of methyl red using LSCCC and LLE were studied for the period of 1 - 15 min. As shown in Figure 6, after 5 min, the efficiency of the extraction was not changed significantly. Hence, a fast five min extraction time was chosen for further studies.

\subsection{Removal of Methyl Red from Real Wastewater}

The real wastewater sample obtained from Baft Azadi Textile Co, Tehran. I. R. Iran. The sample contain various 


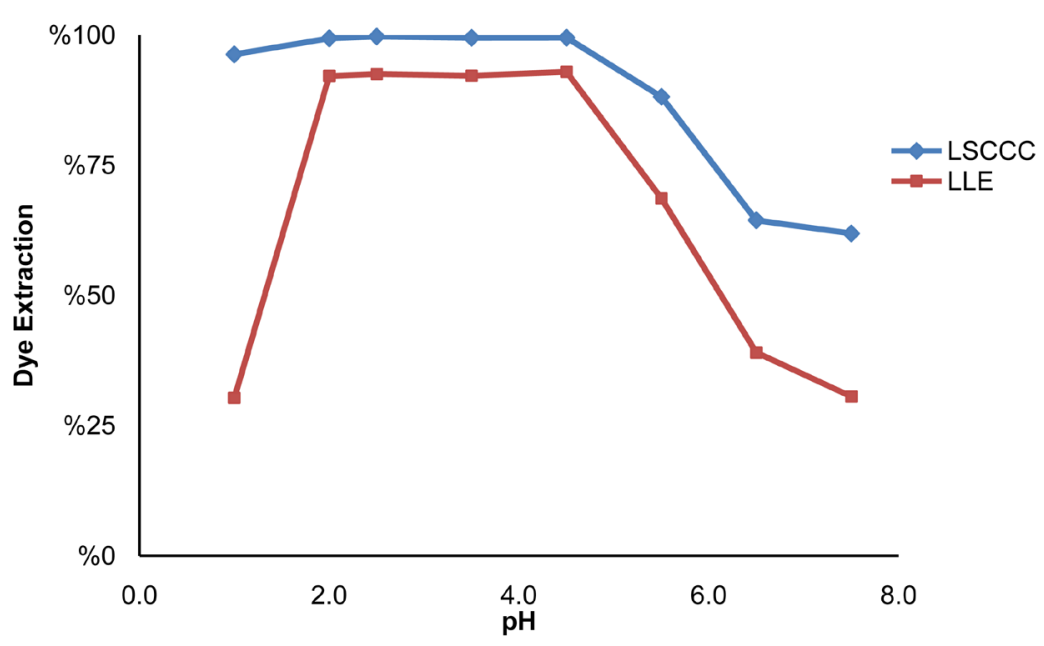

Figure 4. Effect of pH on extraction efficiency of the methyl red. Experimental conditions: solvent system, xylene-water $(1: 1 / \mathrm{v} / \mathrm{v})$, volumeof aqueous phase $=20 \mathrm{~mL}$ at different $\mathrm{pHs}$, volume of organic phase $=20 \mathrm{~mL}$, dye concentration $0.2 \mathrm{mmol} / \mathrm{L}$, equilibration time $=5 \mathrm{~min}$.

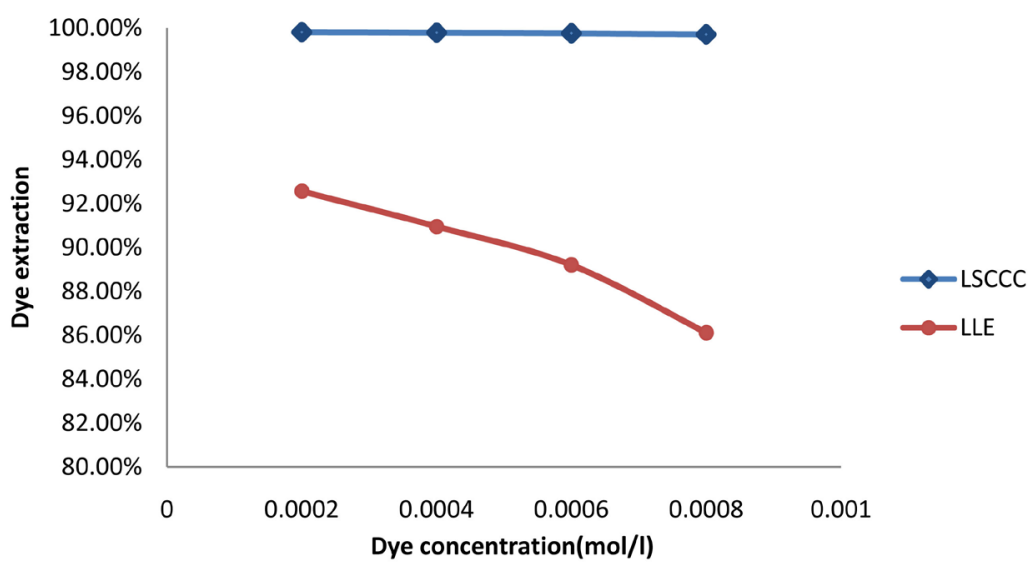

Figure 5. Effect of dye concentration on extraction efficiency of the methyl red. Experimental conditions: solvent system, xylene-water $(1: 1 / \mathrm{v} / \mathrm{v})$. Volume of aqueous phase $=20 \mathrm{~mL}$ at $\mathrm{pH}=2.5$ \pm 0.1 , volume of organic phase $=20 \mathrm{~mL}$, dye concentration $0.2 \mathrm{mmol} / \mathrm{L}$ to $0.8 \mathrm{mmol} / \mathrm{L}$, equilibration time $=5$ min.

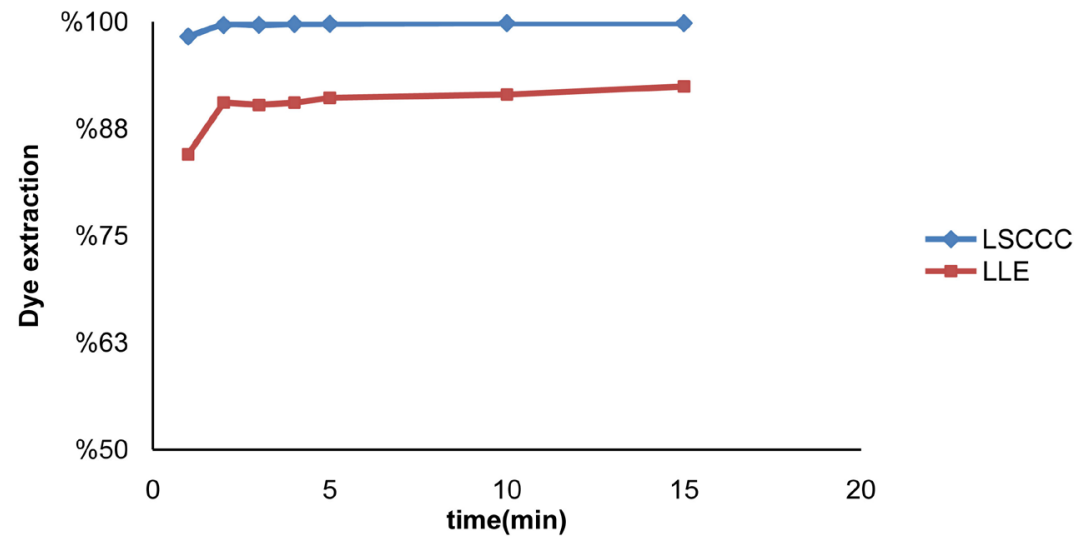

Figure 6. Effect of time in extraction efficiency of the methyl red. Experimental conditions: solvent system, xylene-water $(1: 1 / \mathrm{v} / \mathrm{v})$ volume of aqueous phase $=20 \mathrm{~mL}$ at $\mathrm{pH}=2.5 \pm 0.1$, volume of organic phase $=20 \mathrm{~mL}$, dye concentration $0.2 \mathrm{mmol} / \mathrm{L}$, equilibration time $=1-15 \mathrm{~min}$. 
Table 2. The percentage of re-extraction of methyl red by reused solvent.

\begin{tabular}{cccccccccccc}
\hline No of use & 1 & 2 & 3 & 4 & 5 & 6 & 7 & 8 & 9 & 10 \\
\hline \% of extraction & 99.7 & 99.7 & 99.7 & 99.7 & 99.1 & 98.3 & 91 & 91 & 87.9 & 85.9 \\
\hline
\end{tabular}

types of salts and was alkaline in nature. Optimized conditions were applied and the results of 5 replicate test show that over $98.4 \%$ of the dye could be extracted into organic phase using LSCCC technique. Comparing to synthesis aqueous phase it was concluded that no significant differences between real and synthesis sample has been observed.

\section{Conclusions}

In this study, the aim was extraction of methyl red from wastewater. Methyl red was extracted from aqueous solution by LSCCC. The selected solvent system was xylene-water (1:1 v/v) and xylene (extractant) was used as organic phase. Five various factors were evaluated and it was found that the extraction efficiency was about $99.7 \%$ in just 5 min in the optimal conditions. Maximum extraction was observed in a pH range of 2 to 4.5 .

The importance of this report is not just to propose a new method for extraction of dyes, but also to demonstrate a high efficiency technique which could be used for preparative and large-scale removal of dyes from aqueous phase.

\section{References}

[1] Mahbub, K., Mohammad, A., Ahmed, M. and Begum, S. (2012) Decolorization of Synthetic Dyes Using Bacteria Isolated from Textile Industry Effluent. Asian Journal of Biotechnology, 4, 129-136. http://dx.doi.org/10.3923/ajbkr.2012.129.136

[2] Guo, J., Li, X., Cao, X., Qu, L. and Hou, Y. (2010) Determination of Sudan Dyes in Red Wine and Fruit Juice. International Journal of Environmental Analytical Chemistry, 90, 856-868.

[3] Muthuraman, G. and Teng, T.T. (2009) Extraction and Recovery of Rhodamine B, Methyl Violet and Methylene Blue from Industrial Wastewater Using D2EHPA as an Extractant. Industrial \& Engineering Chemistry Research, 15, 841846. http://dx.doi.org/10.1016/j.jiec.2009.09.010

[4] Songur, R., Bayraktar, E. and Mehmetoglu, U. (2011) Removal of a Reactive Dye by Adsorption Utilizing Waste Aluminium Hydroxide Sludge as an Adsorbent. International Journal of Chemical, Molecular, Nuclear, Materials and Metallurgical Engineering, 5, 56-57.

[5] Faraji, M., Yamini, Y., Tahmasebi, E., Saleh, A. and Nourmohammadian, F. (2010) Cetyltrimethylammonium Bromide-Coated Magnetite Nanoparticles as Highly Efficient Adsorbent for Rapid Removal of Reactive Dyes from the Textile Companies' Wastewaters. Journal of the Iranian Chemical Society, 7, S130-S144.

[6] Cestari, A.R., Vieira, E.F., Vieira, G.S. and Almeida, L.E. (2007) Aggregation and Adsorption of Reactive Dyes in the Presence of an Anionic Surfactant on Mesoporous Aminopropyl Silica. Journal of Colloid and Interface Science, 309, 402-411. http://dx.doi.org/10.1016/j.jcis.2006.11.049

[7] Muthuraman, G., Teng, T.T. and Tan, S.H. (2012) Liquid-Liquid Extraction of Cibacron Red FN-R by TBAB as an Extractant. Desalination, 284, 135-141. http://dx.doi.org/10.1016/j.desal.2011.08.047

[8] Garcia-Montano, J., Domenech, X., Garcia-Hortal, J.A., Torrades, F. and Peral, J. (2008) The Testing of Several Biological and Chemical Coupled Treatments for Cibacron Red FN-R Azo Dye Removal. Journal of Hazardous Materials, 154, 484-490. http://dx.doi.org/10.1016/j.jhazmat.2007.10.050

[9] Geisberger, A. (1997) Azo Dyes and the Law_An Open Debate. Journal of the Society of Dyers and Colourists, 113, 197-200.

[10] Yaneva, Z.L. and Georgieva, N.V. (2012) Insights into Congo Red Adsorption on Agro-Industrial Materials-Spectral, Equilibrium, Kinetic, Thermodynamic, Dynamic and Desorption Studies. International Review of Chemical Engineering, 4, 127-146.

[11] Valarmathi, M., Gomathi, A. and Manisankar, P. (2013) Enhanced Sensing of Anthraquinone Dyes Using Multiwalled Carbon Nanotubes Modified Electrode. International Journal of Environmental Analytical Chemistry, 93, 349-363. http://dx.doi.org/10.1080/03067319.2011.629348

[12] Sahoo, C., Gupta, A. and Pal, A. (2005) Photocatalytic Degradation of Methyl Red Dye in Aqueous Solutions under UV Irradiation Using Ag+ Doped $\mathrm{TiO}_{2}$. Desalination, 181, 91-100. http://dx.doi.org/10.1016/j.desal.2005.02.014

[13] Badr, Y., El-Wahed, M.A. and Mahmoud, M. (2008) Photocatalytic Degradation of Methyl Red Dye by Silica Nano- 
particles. Journal of Hazardous Materials, 154, 245-253. http://dx.doi.org/10.1016/j.jhazmat.2007.10.020

[14] Zougar, S., Baali, S., Jaffrezic-Renault, N. and Kherrat, R. (2014) Gold Electrode Functionalized with Tridodecylamine for Impedimetric Detection of Acid Orange 10. Sensors \& Transducers, 27, 1726-5479.

[15] Bakshi, D.K., Gupta, K. and Sharma, P. (1999) Enhanced Biodecolorization of Synthetic Textile Dye Effluent by Phanerochaete chrysosporium under Improved Culture Conditions. World Journal of Microbiology and Biotechnology, 15, 507-509. http://dx.doi.org/10.1023/A:1008974513785

[16] Ashraf, S.S., Rauf, M.A. and Alhadrami, S. (2006) Degradation of Methyl Red Using Fenton's Reagent and the Effect of Various Salts. Dyes and Pigments, 69, 74-78. http://dx.doi.org/10.1016/j.dyepig.2005.02.009

[17] Divya, N., Bansal, A. and Jana, A.K. (2013) Nano-Photocatalysts in the Treatment of Colored Wastewater. Materials Science Forum, 734, 349-363. http://dx.doi.org/10.4028/www.scientific.net/MSF.734.349

[18] Elumalai, S. and Muthuraman, G. (2014) Recovery of Reactive Dyes from Textile Effluents Using Aliquat 336 as Carrier. International Journal of Innovative Research in Science \& Engineering, 2347-3207.

[19] Dardio, A., Ferro, R., Teiyeira, D., Palace, A.J., Pinto, A.P. and Dias, C.M.B. (2011) Study on the Use of Typha spp. for the Phytotreatment of Water Contaminated with Ibuprofen. International Journal of Environmental Analytical Chemistry, 91, 654-667. http://dx.doi.org/10.1080/03067311003782708

[20] El-Ashtoukhy, E.S. and Fouad, Y. (2015) Liquid-Liquid Extraction of Methylene Blue Dye from Aqueous Solutions Using Sodium Dodecylbenzenesulfonate as an Extractant. Alexandria Engineering Journal, 54, 77-81. http://dx.doi.org/10.1016/j.aej.2014.11.007

[21] Lee, D.W., Hong, W.H. and Hwang, K.Y. (2000) Removal of an Organic Dye from Water Using a Predispersed Solvent Extraction. Separation Science and Technology, 35, 1951-1962. http://dx.doi.org/10.1016/j.aej.2014.11.007

[22] Muthuraman, G., Teng, T.T., Leh, C.P. and Norli, I. (2009) Extraction and Recovery of Methylene Blue from Industrial Wastewater Using Benzoic Acid as an Extractant. Journal of Hazardous Materials, 163, 363-369. http://dx.doi.org/10.1016/j.jhazmat.2008.06.122

[23] Muthuraman, G. and Teng, T.T. (2009) Extraction of Methyl Red from Industrial Wastewater Using Xylene as an Extractant. Progress in Natural Science, 19, 1215-1220. http://dx.doi.org/10.1016/j.pnsc.2009.04.002

[24] Gungor, O., Yilmaz, A., Memon, S. and Yilmaz, M. (2008) Evaluation of the Performance of Calix[8]arene Derivatives as Liquid Phase Extraction Material for the Removal of Azo Dyes. Journal of Hazardous Materials, 158, $202-207$. http://dx.doi.org/10.1016/j.jhazmat.2008.01.060

[25] Geethakarthi, A. and Phanikumar, B. (2011) Industrial Sludge Based Adsorbents/Industrial by Products in the Removal of Reactive Dyes-A Review. International Journal of Water Resources and Environmental Engineering, 3, 1-9.

[26] Han, R., Zhang, J., Zou, W., Shi, J. and Liu, H. (2005) Equilibrium Biosorption Isotherm for Lead Ion on Chaff. Journal of Hazardous Materials, 125, 266-271. http://dx.doi.org/10.1016/j.jhazmat.2005.05.031

[27] Sun, S.P., Li, C.J., Sun, J.H., Shi, S.H., Fan, M.H. and Zhou, Q. (2009) Decolorization of an Azo Dye Orange G in Aqueous Solution by Fenton Oxidation Process: Effect of System Parameters and Kinetic Study. Journal of Hazardous Materials, 161, 1052-1057. http://dx.doi.org/10.1016/j.jhazmat.2008.04.080

[28] Goyal, S., Sharma, G. and Bhardwaj, K. (2009) Decolorization of Synthetic Textile Dye (Methyl Red) Waste Water Using Constructed Wetlands Having Upflow and Downflow Loading Formate. Rasayan Journal of Chemistry, 2, 329331.

[29] Wang, S., Boyjoo, Y., Choueib, A. and Zhu, Z. (2005) Removal of Dyes from Aqueous Solution Using Fly Ash and Red Mud. Water Research, 39, 129-138. http://dx.doi.org/10.1016/j.watres.2004.09.011

[30] Saiful, A.S., Abdul Ghaniey, L.A., Suhardy, D., Farizul, H.K. and Hatim, M.I. (2005) Dye Removal from Aqueos Solution by Using Adsorption on Treated Sugarcane Bagasse. American Journal of Applied Sciences, 2, 1499-1503.

[31] Santhi, T., Manonmani, S. and Smitha, T. (2010) Removal of Methyl Red from Aqueous Solution by Activated Carbon Prepared from the Annona squmosa Seed by Adsorption. Chemical Engineering Research Bulletin, 14, 11-18. http://dx.doi.org/10.3329/cerb.v14i1.3767

[32] Esatbeyoglu, T., Wray, V. and Winterhalter, P. (2015) Isolation of Dimeric, Trimeric, Tetrameric and Pentameric Procyanidins from Unroasted Cocoa Beans (Theobroma cacao L.) Using Countercurrent Chromatography. Food Chemistry, 179, 278-289. http://dx.doi.org/10.1016/j.foodchem.2015.01.130

[33] Ma, X. and Ito, Y. (2015) New Analytical Spiral Tube Assembly for Separation of Proteins by Counter-Current Chromatography. Journal of Chromatography A, 1405, 193-196. http://dx.doi.org/10.1016/j.chroma.2015.05.051

[34] De Beer, D., Joubert, E., Malherbe, C.J. and Brand, D.J. (2011) Use of Countercurrent Chromatography during Isolation of 6-Hydroxyluteolin-7-O- $\beta$-glucoside, a Major Antioxidant of Athrixia phylicoides. Journal of Chromatography A, 1218, 6179-6186. http://dx.doi.org/10.1016/j.chroma.2010.12.096

[35] Mekaoui, N., Chamieh, J., Dugas, V., Demesmay, C. and Berthod, A. (2012) Purification of Coomassie Brilliant Blue 
G-250 by Multiple Dual Mode Countercurrent Chromatography. Journal of Chromatography A, 1232, 134-141. http://dx.doi.org/10.1016/j.chroma.2011.11.022

[36] Bakri, M., Chen, Q., Ma, Q., Yang, Y., Abdukadir, A. and Aisa, H.A. (2015) Separation and Purification of Two New and Two Known Alkaloids from Leaves of Nitraria sibirica by pH-Zone-Refining Counter-Current Chromatography. Journal of Chromatography B, 1006, 138-145. http://dx.doi.org/10.1016/j.jchromb.2015.10.038

[37] Sun, Y., Lin, H., Liu, Z., Yang, S. and Wang, J. (2014) Preparative Separation of Minor Bioactive Compounds from Flower of $P$. cuspidatum by High-Speed Counter-Current Chromatography and Comparison of Their Antioxidant Activity. Separation and Purification Technology, 134, 171-177. http://dx.doi.org/10.1016/j.seppur.2014.07.035

[38] Meng, J., Yang, Z., Liang, J., Guo, M. and Wu, S. (2014) Multi-Channel Recycling Counter-Current Chromatography for Natural Product Isolation: Tanshinones as Examples. Journal of Chromatography A, 1327, 27-38.

http://dx.doi.org/10.1016/j.chroma.2013.12.069 